\title{
Various Biochemical Aspects of the Blood in Experimentally Induced Hyper and Hypoprolactinemia in Male Guinea Pigs
}

\author{
A.A. Yousef, ${ }^{1, *}$ and H. MANSOUR ${ }^{2}$ \\ ${ }^{1}$ Department of Physiology and Biochemistry and ${ }^{2}$ Department of \\ Obstetrics and Gynaecology, Faculty of Veterinary Medicine, \\ Zagazig University, Zagazig, Egypt
}

(Received September 12, 1988)

Summary The present study aimed to investigate various biochemical constituents in serum of male guinea pigs of differing serum prolactin status.

Four similar groups of apparently healthy male guinea pigs were used in this study. The first group was used as the control; the second group was made hyperprolactinemic with daily doses of $1 \mathrm{mg}$ estrogen; the third group was made hypoprolactinemic with daily doses of $2.5 \mathrm{mg}$ bromocriptine; the fourth group, after being similarly dosed with estrogen, was again orally dosed with bromocriptine.

Results revealed that estrogen induced a marked serum hyperprolactinemia accompanied with a significant rise in serum levels of estradiol-17 $\beta$, insulin, and calcium; while serum levels of glucose, magnesium, and inorganic phosphorous were found to be significantly decreased. These serum constituent levels approached to almost their control levels after bromocriptine administration. Bromocriptine without estrogen promoted a marked decrease in serum prolactin and estradiol$17 \beta$, but other serum parameter levels remained almost within their normal range. The biochemical changes detected in the present study may be useful in clinical diagnosis and treatment of prolactinemia.

Key Words: prolactinemia, carbohydrate metabolism, mineral metabolism, clinical diagnosis

The importance of prolactin (PRL) as a lactogenic hormone and its role in the control of reproduction has long been recognized in man $[1,2]$ and in animals $[3$,

*To whom correspondence should be addressed. 
4]. Over-secretion of PRL has been found to be one of the most effective causes of infertility [1-4]. It was reported that PRL over-secretion is augmented by estrogen administration [5-7]. On the other hand, PRL can be suppressed by the dopamine-agonistic effect of certain ergot compounds $[8,9]$ like bromocriptine (BrCR) $[8,9]$. The use of $\mathrm{BrCR}$ in hyperprolactinemic infertility is now well established [9].

There are few reports on the biochemical effect of PRL administration on serum constituents, and PRL administration is known to enhance hepatic glycogen breakdown, as well as intestinal absorption of glucose [10-12], calcium [13], and magnesium [14] but a more detailed study in cases of differing serum PRL status is lacking. Therefore, this present study aimed to investigate the serum levels of glucose, insulin, calcium, inorganic phosphorous, and magnesium in male guinea pigs of differing PRL status. This necessiated the establishment of serum levels of PRL and estrogen. Estrogen and BrCR drugs were used for the respective experimental elevation and depression of serum PRL.

\section{MATERIALS AND METHODS}

Mature male guinea pigs around 10 months of age and weighing from 625 to $650 \mathrm{~g}$ were utilized in this study. The animals were allowed free access to water and food free of phytoestrogens. For the purpose of investigation, animals were divided into 4 groups, each comprising 20 guinea pigs: The animals of group 1 were served as control and represented normoprolactinemic animals. Each animal of group 2 was injected daily intramuscularly with a 1-mg dose of estrogen (Folon-5, Misr Co. for Pharmaceuticals, Egypt) for 21 consecutive days. This group represented hyperprolactinemic animals. The dose used to induce hyperprolactinemia was suggested in a previous investigation [14]. Each animal of group 3 was administered orally a daily dose of $2.5 \mathrm{mg}$ BrCR (Parlodel, Sandoz Ltd., Basel, Switzerland) for 21 consecutive days, which resulted in marked hypoprolactinemia. Each animal of group 4 after being injected intramuscularly with a daily 1 -mg dose of estrogen for 21 consecutive days was again administered orally with a daily dose of $2.5 \mathrm{mg} \mathrm{BrCR}$ for another 21 consecutive days. This group represented hyperprolactinemic BrCR-treated animals.

At the end of the experimental period, the animals of each group were fasted for $12 \mathrm{~h}$ then decapitated. Blood samples collected were left to clot at $37^{\circ} \mathrm{C}$ for 1 $\mathrm{h}$ and centrifuged at 3,000 rpm to separate the serum. Serum levels of PRL [15], estradiol-17 $\beta$ [16], and insulin [17] were assayed by radioimmunoassay. Serum levels of glucose [18], calcium [19], inorganic phosphorous [20] and magnesium [21] were colorimetrically estimated. The data were statistically analysed to ascertain the changes accompanying different treatments using Student's $t$ method [22] to compare experimentals with the control levels. 


\section{RESULTS}

The mean values of different serum biochemical constituents in control and estrogen, $\mathrm{BrCR}$, and estrogen-BrCR treated male guinea pigs are shown in Table 1.

Significant changes in serum levels of various serum constituents studied were recorded in the male animals dosed with estrogen alone. Serum levels of PRL, estradiol-17 $\beta$, insulin, and calcium increased; while those of glucose, inorganic phosphorous, and magnesium were found to be significantly decreased. These levels showed a strong tendency to be restored to their control value after BrCR administration.

BrCR alone exerted a significant decrease in the serum control levels of PRL and estradiol-17 $\beta$; while it produced insignificant changes in the serum level of glucose, insulin, calcium, inorganic phosphorous, and magnesium.

\section{DISCUSSION}

The increased serum PRL activity detected in male guinea pigs dosed with estrogen alone (Group 2), is in agreement with the findings for both sexes in a variety of animals $[5,9,14]$ and in humans $[7,8,12]$. Earlier, it was reported that PRL secretion is augmented by estrogen [8]. A certain investigation demonstrated a modulating role for PRL in 5- $\alpha$ reductase activity and serum elevation of this hormone would accordingly impair dihydrotestosterone synthesis by specific tissues in humans [2]. Dihydrotestosterone is considered to be a reliable indicator of male fertility status $[1,2]$.

Table 1. Levels of various biochemical parameters in the blood of male guinea pigs treated with estrogen or/and bromocriptine.

\begin{tabular}{lcccc}
\hline Serum parameters & Group 1 & Group 2 & Group 3 & Group 4 \\
\hline Prolactin $(\mathrm{ng} / \mathrm{ml})$ & $12.4 \pm 1.3$ & $35.5 \pm 4.6$ & $6.2 \pm 1.1$ & $12.7 \pm 2.5$ \\
& & $(+23.1)^{* *}$ & $(-6.2)^{* *}$ & $(+0.3)$ \\
Estradiol-17 $\beta(\mathrm{pmol} / \mathrm{ml})$ & $95.9 \pm 3.1$ & $520.6 \pm 25.6$ & $85.7 \pm 2.1$ & $92.1 \pm 4.0$ \\
& & $(+424.7)^{* *}$ & $(-10.2)^{*}$ & $(-3.8)$ \\
Insulin $(\mu \mathrm{U} / \mathrm{ml})$ & $4.5 \pm 0.6$ & $7.8 \pm 0.7$ & $4.4 \pm 0.3$ & $4.6 \pm 0.7$ \\
& & $(+3.3)^{* *}$ & $(-0.1)$ & $(+0.1)$ \\
Glucose $(\mathrm{mg} / \mathrm{dl})$ & $96.7 \pm 2.5$ & $87.7 \pm 3.6$ & $95.8 \pm 3.6$ & $93.2 \pm 4.3$ \\
& & $(-9.0)^{*}$ & $(-0.9)$ & $(-3.5)$ \\
Calcium $(\mathrm{mg} / \mathrm{dl})$ & $10.1 \pm 1.1$ & $14.3 \pm 1.1$ & $11.1 \pm 2.1$ & $10.9 \pm 2.2$ \\
& & $(+4.2)^{*}$ & $(+1.0)$ & $(+0.8)$ \\
Inorganic phosphorous & $5.5 \pm 0.2$ & $3.8 \pm 0.1$ & $5.3 \pm 0.2$ & $5.4 \pm 0.1$ \\
(mg/dl) & & $(-1.7)^{* *}$ & $(-0.2)$ & $(-0.1)$ \\
Magnesium (mg/dl) & $2.9 \pm 0.2$ & $2.0 \pm 0.1$ & $2.8 \pm 0.1$ & $2.5 \pm 0.3$ \\
& & $(-0.9)^{* *}$ & $(-0.1)$ & $(-0.4)$ \\
\hline
\end{tabular}

Values in parentheses indicate the differences either an increase $(+)$ or decrease $(-)$, resulting after various treatments. ${ }^{*} p \leq 0.01 ;{ }^{* *} p \leq 0.001$.

Vol. 6, No. 1, 1989 
The strong PRL-inhibitory action of BrCR administration either in normoprolactinemic or in hyperprolactinemic male guinea pigs noticed in this study may be attributed to its strong competitive action with other substances exhibiting high affinity for dopamine receptors [8]. Our results are in harmony with those reported for experimental hyperprolactinemia in animals $[9,14]$, normoprolactinemic women [23] as well as for humans with PRL-secreting pituitary tumors [24], all of which showed a significant decrease in serum or plasma PRL activity during BrCR administration.

The highly significant increase in serum estradiol-17 $\beta$ in male animals given estrogen followed by a marked decrease after BrCR administration agree well with the findings in women [25] and female guinea pigs [14].

The recorded hypoglycaemia in estrogen-treated male guinea pigs as noticed in the present study (Table 1) may be attributed to the resulting hyperinsulinemia attained by the animals as a response to estrogen injection [14] or to released PRL $[12,14]$. As hypothesized by other investigators [26], although PRL as well as growth hormone is usually thought of as diabetogenic, yet, it is important to note that they may have an insulin-like action in animals. In contrast to our findings, certain other investigators mentioned that PRL elevation induces hepatic glycogen breakdown associated with increased intestinal absorption of glucose in experimental hyperprolactinemia induced by PRL administration in animals [12].

The increase in serum calcium in experimental hyperprolactinemia after estrogen administration may be attributed to PRL release, for PRL may act to increase the intestinal absorption of calcium, which would in turn increase its level in serum as hypothesized by other investigators $[12,13]$.

The low serum inorganic phosphorous after estrogen administration as shown in Table 1, is probably due to high serum estradiol-17 $\beta$ which would accordingly lower both appetite as well as intestinal absorption of phosphorous as reported by other investigators [27]. Another suggestion is that the decreased serum inorganic phosphorous could be attributed to increased level of insulin in the blood leading to increased metabolism of glucose involving inorganic phosphorous which may be the reason of inorganic phosphorous depletion in serum observed in this study [28].

The recorded decrease in serum magnesium in animals made hyperprolactinemic with estrogen is probably due to increased deposition of this mineral in liver and muscles as suggested by other studies in animals [14]. A decrease in inorganic phosphorous was noticed in experimentally induced hypomagnesemia in buffaloecalves [28]. Our results shown in Table 1 revealed a significant decrease in serum magnesium after estrogen administration, which also suggests a closer connection between magnesium and inorganic phosphorous metabolism.

In the estrogen-BrCR-treated group, serum levels of various biochemical constituents under investigation showed a strong tendency to regain their control levels.

Serum biochemical constituent levels of both PRL and estradiol-17 $\beta$ de- 
creased to less than their control values after BrCR administration, but other serum constituent levels remained within their normal range. This could be attributed to lack of estrogen effect [8].

The biochemical changes noted here may be useful for clinical diagnosis and treatment of different types of PRL abnormalities.

\section{REFERENCES}

1. Micic, S., Dotlic, R., and Ilis, D. (1985): Serum testosterone and estradiol in infertile men with hyperprolactinemia, 5th World Congress on Human Reproduction, Abstract No. 56, Athens, Greece.

2. Magrini, G., Ebiner, J.R., Burckhardt, P., and Felder, J.P. (1976): Study on the relationship between plasma prolactin levels and androgen metabolism in man. J. Clin. Endocrinol., 43, 944-947.

3. Heshmat, H., Yousef, A.A., and El-Azawy, A. (1987): Hyperprolactinemia in male rat, 5th Forum of International Andrology, Report-I, Paris.

4. El-Azawy, A., Yousef, A.A., and Heshmat, H.A. (1987): Hyperprolactinemia in male rat, 5th Forum of International Andrology, Report-II, Paris.

5. Chen, L., and Mites, J. (1970): Serum prolactin level in rats with pituitary transplants on hypothalamic lesions. Neuroendocrinology, 6, 220-225.

6. Kato, H., Velasco, M.E., and Rothchild, I. (1978): The role of hypothalamus in the tonic secretion of prolactin induced by estrogen. Acta Endocrinol., 89, 417-424.

7. Frantz, A.O., Kleinberg, D.L., and Noel, G.L. (1972): Studies on prolactin in man. Recent Prog. Horm. Res., 28, 527-530.

8. Del-Pozo (1982): Hyperprolactinemia in Man, in Treatment of Male Infertility, ed. by Bain, J., Schill, W.B., and Schwarzstein, L., Springer-Verlag, Berlin, Heidelberg and New York, pp. 71-84.

9. Backry, H., Hesmat, H., Yousef, A., and El-Moussallamy, E. (1987): Toxicological and biochemical studies on bromocriptine as a drug used in the treatment of hyperprolactinemia in male rabbits, Proceedings of 1st Scientific Congress, Future of Rabbit Production in Egypt, 20-25, Ismailia, Egypt.

10. Yousef, A.A., Hussein, Y.M., and Heshmat, A.A. (1988): Some biochemical and histological changes during experimentally induced hyperprolactinemia in male rabbits. J. Clin. Biochem. Nutr., 4, 191-196.

11. Landgraf, R., Landgraf, M., Weissman, A., Hori, R., von Werder, K., and Scariba, P.C. (1977): Prolactin: A diabetogenic hormone. Diabetologia, 13, 99-105.

12. Horrobin, D.E. (1978): Prolactin: Effect and Clinical Significance, Vol. 6, Chapter 14, Churchill Livingstone, Annual Research Review, pp. 77-87.

13. Robinson, C.J., Mahajan, K.K., and Horrobin, D.E. (1974): Some effects of prolactin on calcium metabolism. Proc. Soc. Endocrinol., 66, 27-30.

14. El-Sadawy, H.A., Bareedy, M.H., El-Azawy, A.I., and Balah, A.M. (1986): Biochemical, histochemical and histological studies on estrogenic and bromocriptine treated estrogenic non-pregnant guinea pigs. Zagazig Vet. J., 14, 21-47.

15. Hwang, P., Guyda, H., and Friesen, H.G. (1971): A radioimmunoassay for serum prolactin. Proc. Natl. Acad. Sci. USA., 68, 192-199.

16. Mikiel, G., Girin, M., and Vang, R.L. (1970): The method of estimation of estradiol $17 \beta$ using radioimmunoassay technique. Steroids, 15, 333-340.

17. Wilson, S., and Miles, L. (1977): Radioimmunoassay of insulin in plasma, in Handbook of Radioimmunoassay, ed. by Abraham, G.E., Dekker, M., New York, pp. 257-260.

18. Torlotin, J.C. (1966): Determination of glucose in body fluids by orthotoluidine method. Am. Biol. Clin., 24, 173-175.

Vol. 6, No. 1, 1989 
19. Gindler, E.M., and King, J.D. (1972): Rapid colorimetric determination of calcium in biological fluids with methyl thymol blue. Am. J. Clin. Pathol., 58, 376-383.

20. Trinder, P. (1960): Colorimetric determination of phosphorous, in Microanalysis in Medical Biochemistry. (Fide, Wootton, I.D.P. 1964. J. \& A. Churchill Ltd., London.)

21. Gindler, E.M., and Heth, D.A. (1970): Colorimetric determination of magnesium in serum with polyvinyl pyrrolidine-bound calmagite. Chicago Clin. Chem., 3, 37-40.

22. Snedecor, G.W., and Cochran, W.G. (1967): Statistical Methods (6th ed.), Iowa State University Press, Iowa.

23. Amos, W.L. (1984): Successful treatment of infertility with bromocriptine mesylate after failure of clomiphene in anovulatory patients. Adv. Therapy, 1, 343-348.

24. Nillius, S.J. (1980): Medical therapy of prolactin-secreting pituitary tumors, in Advances in Prolactin, ed. by Hermite, M., and Judd, L., Karger, Basel, Vol. 6, pp. 194-218.

25. Villalobos, H., Canales, E.S., Zarata, A., Soria, J., and McGregor, C.C. (1976): Effect of prolactin suppression on gonadotrophic secretion in the puerperium. Acta Endocrinol., 83, 236-243.

26. Kostyo, J.L., and Regan, C.R. (1976): The biology of growth hormone. Pharmacol. Ther., 2B, 591-597.

27. Sakukar, C.S., Pandit, R.K., Chauhan, R.A.S., and Porwal, M.L. (1984): Electrolytes during various reproductive phases in crossbred cows. Indian J. Anim. Sci., 54, 993-995.

28. Doxy, D.L. (1971): Serum minerals in experimentally induced hypomagnesemia in animals, in Veterinary Clinical Pathology, Bailliare, Tindal, London, pp. 55-58. 